\title{
Assessment of Commercial Active Ceramic Tiles on Benzene Degradation for the Pollution Control of Indoor Atmospheric Buildings
}

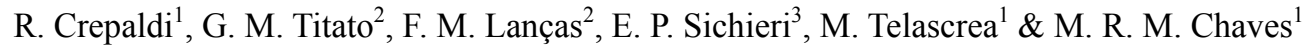 \\ ${ }^{1}$ Pró-Reitoria de Pesquisa e Pós-Graduação, Universidade do Sagrado Coração, Bauru, Brazil \\ ${ }^{2}$ Institute of Chemistry, University of São Paulo, São Carlos, SP, Brazil \\ ${ }^{3}$ Institute of Architecture and Urbanism, University of São Paulo, São Carlos, SP, Brazil \\ Correspondence: Marcia R. M. Chaves, Pró-Reitoria de Pesquisa e Pós-Graduação, Universidade do Sagrado \\ Coração, Bauru, SP., Rua Irma Arminda, 10-50, Bloco K, Brazil. Tel: 55-14-2107-6970. E-mail: \\ marcia.chaves@usc.br
}

Received: August 9, 2017

doi:10.5539/jsd.v10n5p257
Accepted: September 8, $2017 \quad$ Online Published: September 29, 2017

URL: https://doi.org/10.5539/jsd.v10n5p257

\begin{abstract}
Volatile Organic Compounds (VOCs) constitutes an important class of air pollutants, and benzene is one of the main contaminants of indoor air pollution. Among the methods for the treatment of environments with a high VOCs concentration is the photocatalytic oxidation by $\mathrm{TiO}_{2}$ (anatase) ceramic coated surfaces. The effectiveness of VOCs photodegradation studies using active ceramic tiles made in laboratory is well reported in the literature. However, this has not been reported using commercial tiles, although active ceramics are sold for such a function. In this context, this study proposed the assessment of commercial active ceramic tiles capacity in the photocatalytic degradation of benzene in indoor air. The development of this work arose from two questions: a) if the commercial active ceramic tiles are efficient in the VOCs degradation as the manufacturers claim; $b$ ) if they are able to degrade VOCs in indoor building environments. Experiments were conducted in laboratory's scale, using an adapted simulation chamber. The volatilized benzene entered in contact with the commercial ceramic tile under fluorescent light and ultraviolet (UV) light of $365 \mathrm{~nm}$. Samples of the chamber internal air were collected by adsorption on polydimethylsiloxane fibres in headspace technique (SPME-HS). The evaluation of the benzene degradation occurred by gas chromatography analysis with mass spectrometry (GC-MS). The characterization of commercial active ceramic samples occurred by techniques of X-Ray Diffraction Powder (XRD), and Scanning Electron Microscopy (SEM) with Energy Dispersive Spectrometry (EDS). Results showed that, under the experimental conditions, the commercial active ceramic tile was not capable of the benzene photocatalytic oxidation. The ceramic characterization detected very low quantity of $\mathrm{TiO}_{2}$ on ceramic samples, being this fact attributed as the main responsible for the ceramic photocatalytic inactiveness.
\end{abstract}

Keywords: air pollution control, active ceramic, photocatalysis, sustainable buildings

\section{Introduction}

The air pollution and its effects on human health have become a great concern, and the focus of numerous discussions and scientific studies (van der Zee, Fischer, \& Hoek, 2016; Zhang \& Wang, 2010). Among the air pollutants, Volatile Organic Compounds (VOCs) are considered the most dangerous. The main VOCs harmful to human health are: benzene, toluene, xylene, formaldehyde, and acetaldehyde (EPA, 2009). Others harmful air pollutants include substances such as the volatiles compounds emitted from tobacco smoke and $\mathrm{NO}_{\mathrm{x}}($ Gallego, Roca, Perales, \& Guardino, 2009; Huang et al., 2016). VOCs are considered narcotics, depressants of the central nervous system, and irritating to the respiratory tract and skin (ATSDR, 2007).

VOCs are in higher concentration in indoor air than the outdoor (Mirzaei, Leonardi, \& Neri, 2016), and the exposure to these substances may lead to human neurological changes and cancer development (Schirmer, Pian, Szymanski, \& Gauer, 2011). Thus, it is imperative the air treatment to minimize the pollution, and consequently, the adverse effects on the human health and life quality. This exposure is favoured since most humans spend long periods indoors, such as in commercial and residential buildings (Zhang \& Wang, 2010). The solution for this issue is addressed to the indoor pollution prevention, pollutants dilution by ventilation, or indoor air cleaning 
(EPA, 2009).

Several techniques are available to indoor air cleaning, such as pollutants sorption, membrane separation, and biological treatment (Guieysse et al., 2008; Zhang \& Wang, 2010). Among of them, photocatalytic oxidation (PCO) has attracted the attention due to its efficiency in degrade VOCs from the indoor air (Huang et al., 2016).

The discovery of the photocatalysis phenomenon by titanium dioxide $\left(\mathrm{TiO}_{2}\right)$ nanostructures (Fujishima \& Honda, 1972) derived many researches on the degradation of hazardous recalcitrant compounds (Czech \& Buda, 2015; Hashimoto, Irie, \& Fujishima, 2005). Most of these studies are related to the treatment of contaminated liquid effluents, and the PCO efficiency in this matrix has been demonstrated.

The photocatalytic properties of $\mathrm{TiO}_{2}$ are well established in the literature, being anatase the most active crystalline form to promote this phenomenon ( Alijani et al, 2017; Bianchi et al, 2017; Diamanti et al., 2013; Diebold, 2003). However, to the practical application, it is required the $\mathrm{TiO}_{2}$ support on diverse materials to compose the PCO system.

Ceramic materials, paints, and Heating, Ventilating, and Air Conditioning (HVAC) systems, including air filters, are the main supports to $\mathrm{TiO}_{2}$. Studies on the HVAC systems supporting $\mathrm{TiO}_{2}$ demonstrated a lack of efficiency for VOCs degradation from indoor air (Hodgson, Destaillats, Sullivan, \& Fisk, 2007). Photocatalytic paints are pointed out as a promised material to $\mathrm{NO}_{\mathrm{x}}$ and some VOCs oxidation, and already is available in commercial scale (AQEG - Air Quality Expert Group, 2016; Laufs et al., 2010).

Studies on ceramic coated with $\mathrm{TiO}_{2}$ to work as self-cleaning surfaces (as well as photocatalytic surfaces to $\mathrm{NO}_{\mathrm{x}}$ and VOCs oxidation) have been conducted. The efficiency of the active ceramic tiles on photocatalytic degradation of the main VOCs present in indoor air, including benzene, was reported (C. L. Bianchi et al., 2013; Hasmaliza, Foo, \& Mohd, 2016; Hofer \& Penner, 2011; Knook \& Maanen, 2013). Also, the efficiency of the benzene degradation by $\mathrm{TiO}_{2}$ supported on diatomite was described by (Cheng, Kang, \& $\mathrm{Li}, 2012$ ).

Despite the great number of researches that demonstrate the efficiency of the active ceramics in the VOCs degradation, there is a lack of information that guarantees the efficiency of these ceramics on a commercial scale. This is particularly important because the active ceramics have been used to obtain certificates of sustainability projects in commercial buildings (e.g. LEED).

It is very important the development of studies on the efficiency of commercial active ceramic tiles to ensure their operation and consequently, the air quality. In the research of Chen, Zhang and Zhang (Chen, Zhang, \& Zhang, 2005) on PCO devices efficiency, the authors concluded that the systems might not work as advertised, and some devices indicate that the PCO is missing or bad placed in the system.

To contribute to this issue, this work evaluated the efficiency of a commercial active ceramic tile on the benzene photocatalytic degradation in confined air. These ceramics are based on the Hydrophilic Tile (HT) technology $\left(\mathrm{TiO}_{2}\right.$ coating) which provide photocatalytic and self-cleaning properties (Solutions, n.d.). Thus, it was hypothesized that the active ceramic tiles should be used for the benzene removal from indoor air, contributing to the air pollution control. Benzene was chosen because it is a common VOC substance present in household cleaners, tobacco smoke, car fumes, as well as furniture materials (Bruno, Caselli, de Gennaro, Iacobellis, \& Tutino, 2008).

\section{Method}

The commercial active ceramic tiles (KeraGail) were purchased from Gail Brazil. The specification of this material reports as consisting in extruded ceramic with active surface based on the HT technology. These ceramics are used to build ventilated façade with an environmental appeal of air pollution control and energy saving.

Two tiles were randomly collected from the others produced and sold to this study. The tiles $(1.20 \times 0.30 \times 0.02 \mathrm{~m})$, colour $290 \mathrm{H}$ white, were washed with neutral detergent and potable water. After cut, the tile samples were rinsed with deionized water and dried at $100^{\circ} \mathrm{C}$ before use.

\subsection{Photocatalytic Properties}

To carry out the benzene degradation study in the simulation chamber, the commercial ceramic tile was cut in pieces of $8 \mathrm{~cm}$ in height and $18 \mathrm{~cm}$ in length, using water jet high pressure equipment (60,000 psi) IFB 3030 model from FLOW (Kent, USA).

To the photocatalysis purpose, it was evaluated the fluorescent and ultraviolet (UV) $365 \mathrm{~nm}$ lamps, T5 type $4 \mathrm{~W}$, with $150 \mathrm{~mm}$ total length and $15 \mathrm{~mm}$ diameter, as light sources.

To simulate the environment internal air of a building, a glass desiccator $(250 \mathrm{~mm}$ internal diameter; $12 \mathrm{~L}$ total 
volume) was adapted as a simulation chamber. The simulation chamber was set up as showed in the Figure 1.

Inside the chamber, over the perforated porcelain plate, two commercial active ceramic pieces were arranged in holders to stand upright, simulating the position in a building wall (Figure 1a-d). Also, a micro fan (12v; $4 \mathrm{~cm} \mathrm{x}$ $4 \mathrm{~cm}$ ) was placed to promote the benzene distribution on the entire chamber, and a glass Beaker with $20 \mathrm{~mL}$ distilled water was placed to keep the air humidity (Figure 1a). A dichroic $30 \mathrm{~W}$ lamp was placed below the perforated porcelain plate, centred at the main hole, used to heat, and volatilizes the benzene (Figure 1a, d).

On the desiccator cover were installed the support for the UV lamps connection; holes (septum) for the sampling of the internal air; as well as an opening for the thermohygrometer external probe, and the power cords of the micro fan and the dichroic lamp (Figure 1e). The temperature and relative humidity were determined by a portable thermohygrometer (Simpla TH02).

Benzene ( $20 \mu \mathrm{L}$; Merck) was completely volatilized by heating (using dichroic lamp) to the total volume of the chamber. The system was left to equilibrate during 15 minutes under forced internal ventilation, and the dichroic lamp was maintained on throughout the experiment to assist in the equilibrium of benzene vapor in the chamber. After that, the lamp (UV or fluorescent) was switch on, and the benzene content evaluated at intervals of 30 to 120 minutes, by gas chromatography-mass spectrometry with sample collection in headspace by solid phase micro extraction (SPME - HS).
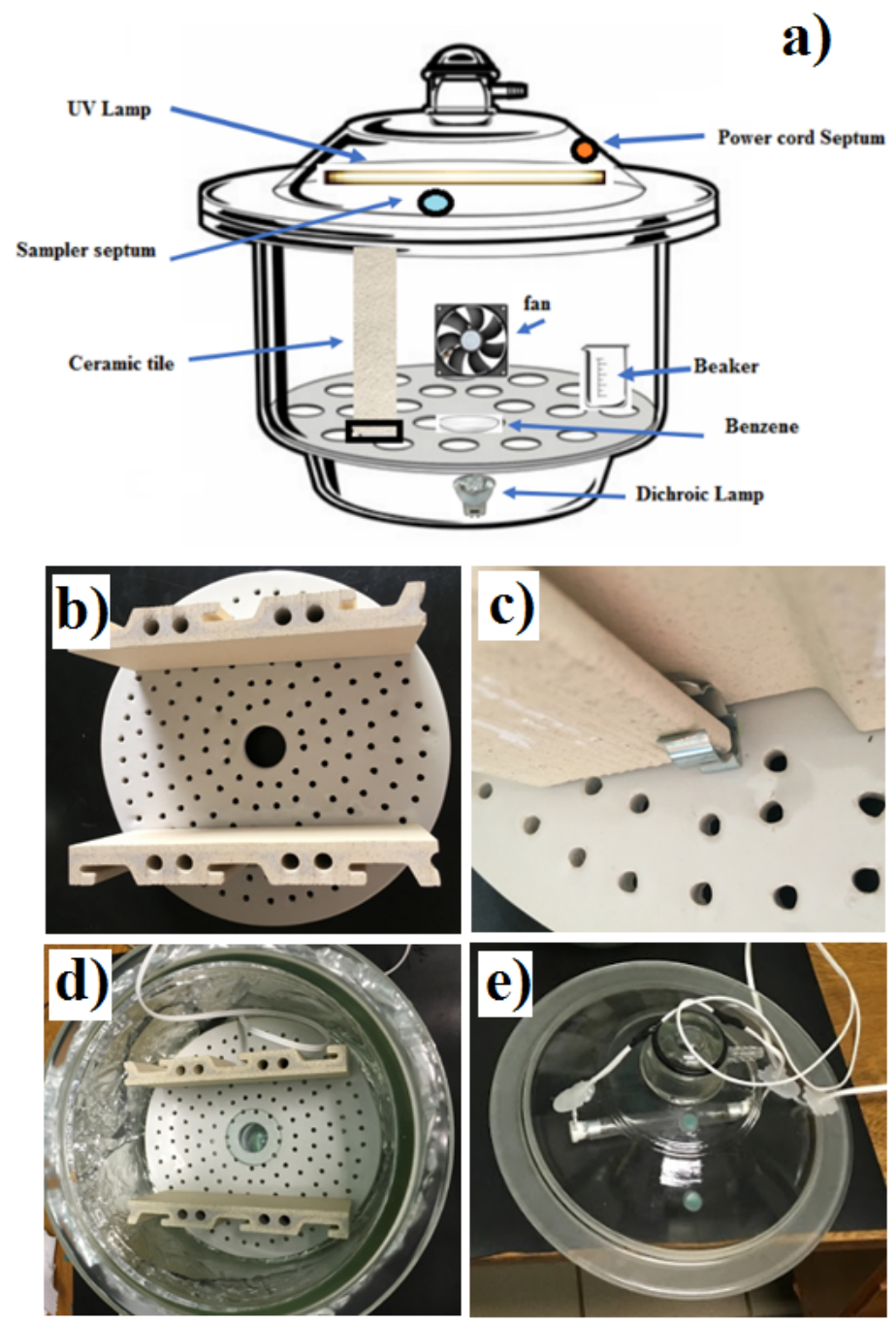

Figure 1. Simulation chamber design for the experimental benzene photocatalytic degradation study: a) simulation chamber illustration; $b$ ) ceramic tiles on the perforated plate; c) detail of the ceramic tile fixation; d) overview of internal chamber with ceramic tiles and dichroic lamp; e) detail of the chamber cover with the UV lamp and wires 
The adsorbent fibres were 100\% polymethylsiloxane (PDMS) Supelco (Bellefonte, PA, USA), specific for benzene extraction in solid phase. The fibres exposure time to the internal air of the chamber was 10 minutes. The same fibres were used in all analyses.

The equipment used was a Shimadzu GC17A coupled to the mass spectrometer Shimadzu QP5050A, simple quadrupole. The column used was DB-5MS (5\% phenyl, $95 \%$ polydimethylsiloxane) of $30 \mathrm{~m}$ length; $0.25 \mathrm{~mm}$ internal diameter; $0.25 \mu \mathrm{m}$ of stationary phase thickness. The GC analysis used gas Helium $99.995 \%$; flow rate of $0.5 \mathrm{ml} / \mathrm{min}$; linear velocity of $26.5 \mathrm{~cm} / \mathrm{s}$; fixed column temperature of $120^{\circ} \mathrm{C}$. In the benzene analysis, the $\mathrm{m} / \mathrm{z}$ 78 (relative to the molecular ion) was monitored. The elution time of the column was $2.1 \mathrm{~min}$. The ASTM D6420-99 (2004) - Test Method Standard for VOC Determination by direct interface between Gas Chromatography and Mass Spectrometry was used.

\subsection{Ceramic Characterization}

The commercial active ceramic tile was characterized using X-Ray Powder Diffraction (XRD) and Scanning Electron Microscopy (SEM) with microanalysis by Energy Dispersive X-ray Spectroscopy (EDS). The analyses are used to identify the chemical composition of the ceramic material in each sample, as well as to identify the presence of the different $\mathrm{TiO}_{2}$ crystalline phases (rutile and anatase) on the surface of the commercial active ceramic tile.

XRD analyses were performed using bulk (sample 1) and surface (sample 2) ceramic samples after manual grinding with an agate mortar. XRD analyses were performed with a Rigaku diffractometer (DMAX) using $\mathrm{CuK \alpha 1}(1.5818 \AA)$ radiation, operating at $40 \mathrm{kV}$ and $20 \mathrm{~mA}$. Scans were performed from 10 to $80^{\circ}(2 \theta)$ at a step size of $0.02^{\circ}$ with a scan speed of $2^{\circ} / \mathrm{min}$. XRD data were interpreted by using the RRUFF mineralogical databases (Lafuente, Downs, Yang, \& Stone, 2015).

The scanning electron microscopy (SEM) was used to evaluate the surface morphology of the ceramic and $\mathrm{TiO}_{2}$ film dimensions. The samples were analysed in Zeiss EVO 50 equipment. A thin layer of gold was prior deposited by sputtering on the samples through the Bal-Tec SCD 050 equipment, for better definition in the contrasts of the images. The chemical composition of the samples was obtained as a semi-quantitative analysis of elemental microanalysis given by energy dispersive spectrometer (EDS). The IXRF Systems 500 Digital Processing detector coupled to the SEM was used.

\section{Results and Discussion}

\subsection{Photocatalytic Properties of the Commercial Active Ceramic}

The formulated hypothesis that the commercial active ceramic tiles are capable to the benzene degradation was evaluated. Thus, the photocatalytic properties of the commercial active ceramic tiles were evaluated under two light sources: fluorescent, to simulate the sun light, and UV $(365 \mathrm{~nm})$. The reference condition was a blank (without the ceramic plate). Several previous experiments (data not shown) were done to define the optimal conditions to run the tests, and to evaluate the ceramic photocatalytic properties. GC-MS results are summarized in the Table 1.

The dichroic lamp was left on during the test, allowing the complete benzene volatilization. The internal chamber temperature in 120 minutes of the experiments was $48.1 \pm 1.2^{\circ} \mathrm{C}$ and $46.2 \pm 1.7^{\circ} \mathrm{C}$ for fluorescent and UV light, respectively. Similarly, the relative humidity was $92 \%$ for both experiments. According the ceramic manufacturer, the tile surface is hydrophilic, thus, the humidity inside the chamber was enough to favour the photocatalytic process. However, the high temperature should limit the photodegradation process, since it can affect the adsorption process of the pollutants on the ceramic surface.

The Relative Standard Deviations (RSD) reflects the precision between each peak area founded in each step (0 to $120 \mathrm{~min}$ ) of same experiment. The analytical validation for chromatograph methods followed the standards $8260 \mathrm{~B}$ and 8000D of Environmental Protection Agency (EPA) protocols, being the RSD given by equation (1).

$$
\operatorname{RSD}(\%)=\left(\frac{\text { Standard Deviation of Peak Areas }\left(t_{0}, t_{120}\right)}{\text { Averageof Peak Areas }\left(t_{0}, t_{120}\right)}\right) \times 100
$$


Table 1. Experimental results of benzene degradation in the simulation chamber: tests performed using commercial ceramic tiles with and without fluorescent light, and UV light $365 \mathrm{~nm}$ (values referred as average of duplicate experiment)

\begin{tabular}{|c|c|c|c|c|}
\hline \multirow[t]{2}{*}{ Exposure time (min) } & \multicolumn{4}{|c|}{$\begin{array}{c}\text { Benzene peak area } \\
\qquad(\mathrm{m} / \mathbf{z} 78)\end{array}$} \\
\hline & $\begin{array}{c}\text { Fluorescent light } \\
\text { without ceramic tile }\end{array}$ & $\begin{array}{c}\text { Fluorescent light } \\
\text { with } \\
\text { ceramic tile }\end{array}$ & $\begin{array}{c}\text { UV light } \\
(365 \mathrm{~nm}) \text { without ceramic tile }\end{array}$ & $\begin{array}{c}\text { UV light } \\
\text { (365 nm) } \\
\text { with } \\
\text { ceramic tile }\end{array}$ \\
\hline 0 & 3061468 & 2764696 & 3237381 & 3412330 \\
\hline 30 & 2564114 & 2267921 & 2449667 & 3140692 \\
\hline 60 & 2297150 & 1994436 & 2767056 & 2889628 \\
\hline 90 & 2198749 & 2042602 & 2543113 & 2690712 \\
\hline 120 & 2134250 & 1815391 & 2227488 & 2221990 \\
\hline RSD (\%) & 15.44 & 16.81 & 14.50 & 15.77 \\
\hline
\end{tabular}

The values of the relative standard deviation (\%) of the peak areas found in the GC-MS analyses were very close to each other in all tests. The results indicated that no benzene degradation occurred under the established experimental conditions, since blank tests (without ceramic tile) presented RSD very close from the tests performed with the commercial active ceramic tile (Vas \& Vékey, 2004), independently of the light source.

These results were unexpected, considering prior studies which demonstrated that the HT technology in commercial ceramic is efficient to degrade methylene blue (Neumann, 2013), $\mathrm{NO}_{\mathrm{x}}$ (Graumann, 2013), and acetaldehyde (Kisch, 2011). In addition, the results are in disagreement with the characteristics reported by researches carried out using ceramic with $\mathrm{TiO}_{2}$ coatings, whose photochemical phenomenon was identified for volatile organic compounds, including several components of tobacco (Sannino, Vaiano, Sarno, \& Ciambelli, 2013; Vulić, Rudić, \& Ranogajec, 2013).

Based on the experimental results, the ceramic characterization was necessary to verify the $\mathrm{TiO}_{2}$ active coating conditions, and to find the possible cause of benzene non degradation, before set up new experimental conditions for further tests.

\subsection{Ceramic Characterization}

The X-Ray diffraction technique is widely used to characterize ceramic materials, since it allows the identification of the components and their crystalline phases. The manufacturer of the commercial active ceramics tiles informs that the surface of this ceramic is photoactive due to the presence of $\mathrm{TiO}_{2}$ coating. In this research, this technique is fundamental for the determination of the presence of the photoactive phase of $\mathrm{TiO}_{2}$, anatase.

The X-Ray diffraction patterns of the bulk (Sample 1) and active surface (Sample 2) ceramic samples are showed in the Figure 2a. The XRD pattern of both samples 1 and 2 were characteristic of fired clay material, with presence of mullite and quartz (Figure $2 b$ ).

The XRD patterns indicate that the chemical composition of the bulk and the surface of the active ceramic is essentially the same. This characteristic was unexpected, considering that the photocatalysis phenomenon occurs only at the ceramic surface. Thus, it could address to two possibilities: a) the incorporation of photoactive $\mathrm{TiO}_{2}$ in the ceramic bulk, what should increase the production costs without a relevant advantage to photocatalytic properties, or b) the $\mathrm{TiO}_{2}$ coating is missing. 

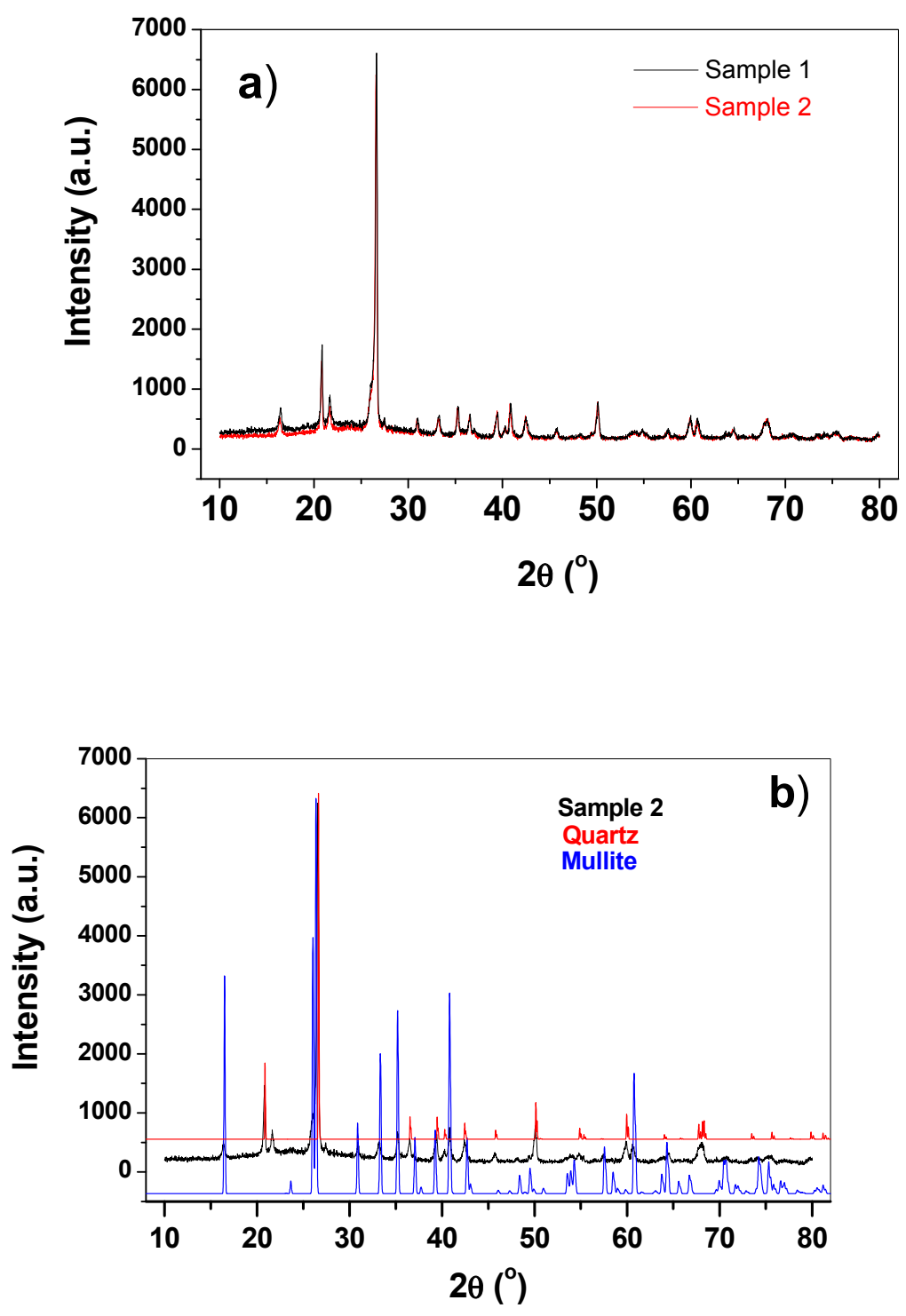

Figure 2. X-ray diffraction pattern of commercial active ceramic samples: a) bulk (sample 1) and surface (sample 2); b) ceramic surface (sample 2), Mullite (RRUFFID: R141101), and Quartz (RRUFFID: R040031)

The XRD diffraction patterns of commercial ceramic samples were then compared to the $\mathrm{TiO}_{2}$ (RRUFF) standard data (Figure 3). The absence of $\mathrm{TiO}_{2} \mathrm{XRD}$ peaks in all ceramic samples was the most worrying observation; since the presence of $\mathrm{TiO}_{2}$ anatase is required for the photocatalytic process occur (Diamanti et al., 2013; Yang et al., 2017). SEM/EDS analyses confirmed this result. 


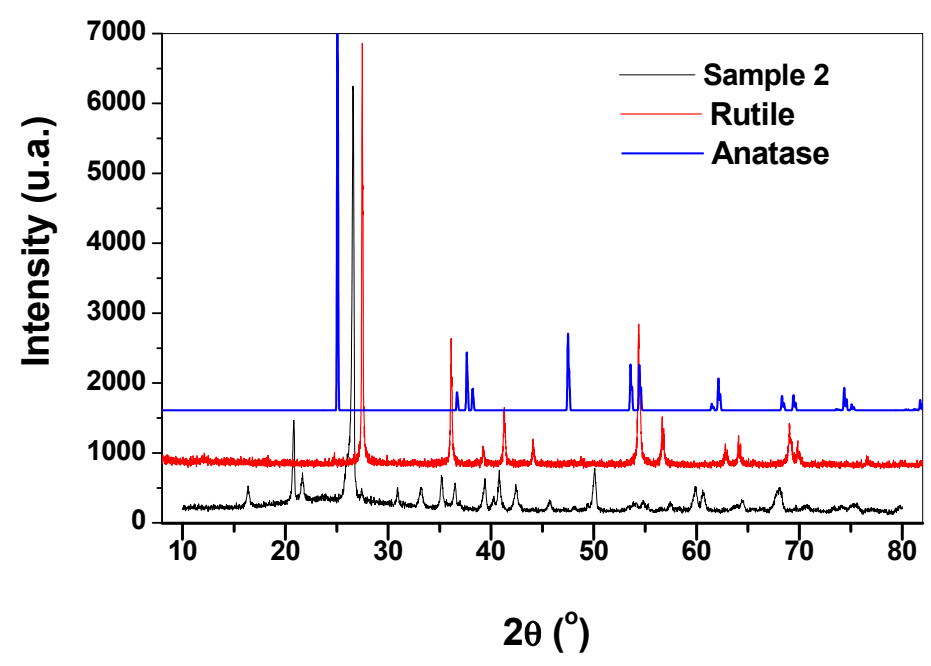

Figure 3. X-ray diffraction pattern of ceramic samples and standard of $\mathrm{TiO}_{2}$ anatase (RRUFFID: R120013) and rutile (RRUFFID: R050031)

The SEM images of ceramic surface revealed rough and porous morphology (Figure $4 \mathrm{a}, \mathrm{b}$ ). To the photocatalysis process take place, it is required the contact of the organic pollutant, water, and $\mathrm{O}_{2}$ on the ceramic surface with active $\mathrm{TiO}_{2}$ and UV radiation. Thus, these characteristics are important to facilitate the organic pollutant adsorption process. In the surface sample of the ceramics evaluated by SEM, the presence of $\mathrm{TiO}_{2}$ nanostructure was not observed as showed in the literature (Knook \& Maanen, 2013; Huang et al, 2016).

The chemical composition revealed in the semi-quantitative analysis of EDS is presented in the Figure 5. The EDS analysis showed the titanium concentration in the surface of ceramic sample at very low level of $0.685 \%$ mass. The main compounds were aluminium and silica, confirming the results obtained by XRD analyses. The occurrence of $\mathrm{TiO}_{2}$ as a natural clay contaminant is between 1.25 and $2.15 \%$ by mass (Petrick et al., 2011), it means that the commercial sample presents less $\mathrm{TiO}_{2}$ than some natural clays.
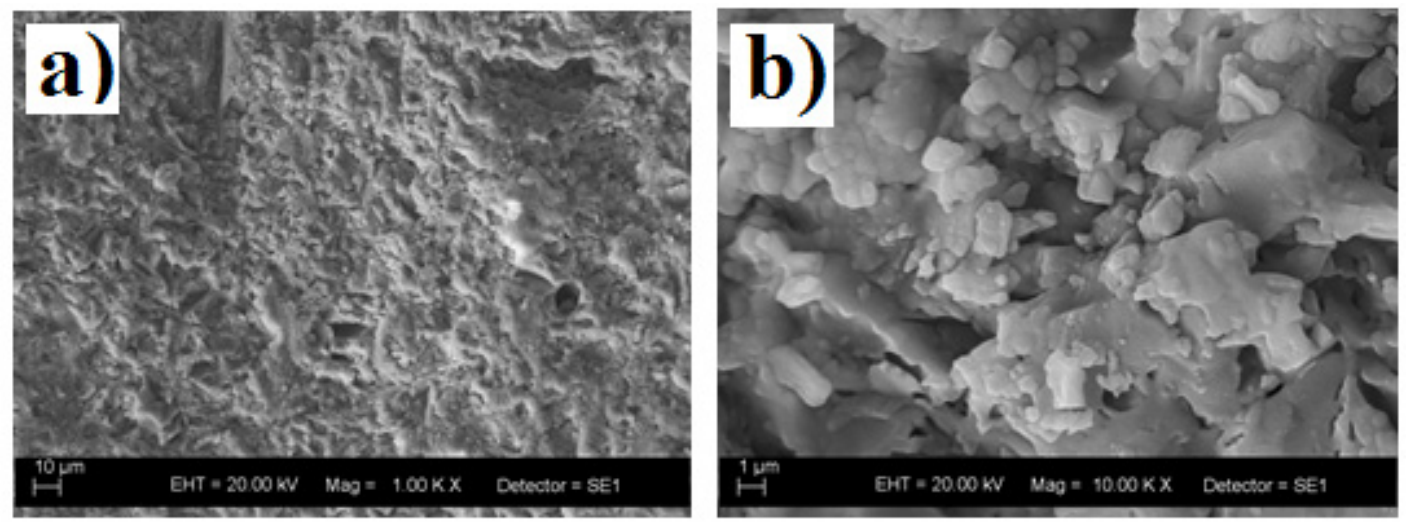

Figure 4. SEM of the commercial ceramic surface; (a) 1,000x magnification; (b) 10,000x magnification 


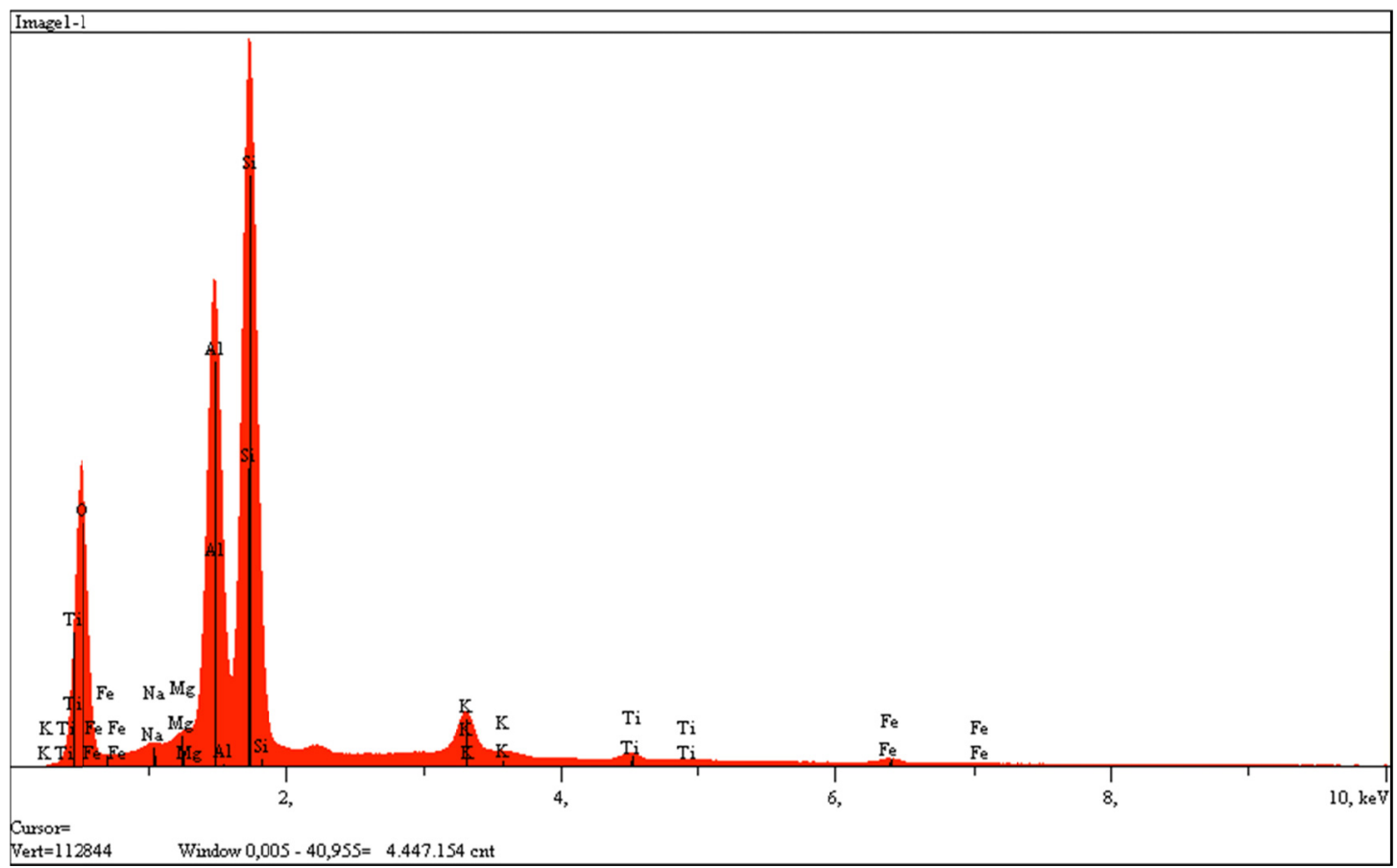

Figure 5. Proportional quantification (mass/mass) $\mathrm{Si} / \mathrm{Ti}$ in the external ceramics surface (XR-microanalysis by EDS)

Several studies on $\mathrm{TiO}_{2}$ supported on ceramic surface report its photocatalytic activity. However, there is no consensus as to the amount of active $\mathrm{TiO}_{2}$ required on the ceramic surface. Vulić et al (Vulić et al., 2013) report 1 to $2 \%$ by mass of anatase to photocatalytic degradation of Rhodamine B. Hadnadjev et al (Hadnadjev et al., 2010) report $2,5 \%$ of $\mathrm{TiO}_{2}$ on the methylene blue photocatalytic degradation. On the other hand, $6 \%$ mass of $\mathrm{TiO}_{2}$ was used by Mohamed et al (Mohamed et al., 2016) in photocatalytic organic dye removal from contaminated water, Hasmaliza et al (Hasmaliza et al., 2016) reported $5 \%$ to $15 \%$ of $\mathrm{TiO}_{2}$ anatase as antibacterial material in ceramic tiles, and $19 \%$ mass on the active ceramic surface reported by Sannino et al (Sannino et al., 2013) to the $\mathrm{NO}_{\mathrm{x}}$ removal from the indoor air.

Despite of the great variation of $\mathrm{TiO}_{2}$ quantity on the ceramic surface demonstrated in the literature, the benzene degradation using the commercial active ceramic tile evaluated in this work was prevented due to the absence of $\mathrm{TiO}_{2}$ in minimum concentration, as results described. This result is in accordance with research findings of Chen, Zhang and Zhang (Chen et al., 2005), once the presence of $\mathrm{TiO}_{2}$ supported on diatomite surface was capable of benzene photodegradation.

The main difference observed between the literature researches and the evaluated commercial active ceramics is that all researchers applied the $\mathrm{TiO}_{2}$ coating on the ceramic surface, being its presence guaranteed. This was enough to produce the photocatalytic phenomenon (Bianchi et al., 2014; Hadnadjev et al., 2010).

Although the mechanical characteristics are described, there is no report available that confirms the surface chemical composition of the evaluated commercial ceramic tiles.

\section{Conclusions}

The assessment of commercial active ceramic tiles on benzene degradation for the indoor atmospheric pollution control of buildings was performed. The results demonstrated that no benzene photodegradation occurs, being attributed to the failure on the active $\mathrm{TiO}_{2}$ coating.

The evaluated commercial ceramics contain $0.685 \%$ wt of $\mathrm{TiO}_{2}$, which showed not sufficient to promote the benzene photocatalytic degradation process. This behaviour launched doubts about its performance in the control of air pollution in buildings that already use this ceramic. Thus, it is imperative the development of certifications and/or specific analytical routine to guarantee the environmental efficiency of the final product, beyond the mechanical quality usually standardized. 


\section{Acknowledgments}

The authors are grateful to Ministry of Education of Brazil, National Council for Scientific and Technological Development - CNPq, Mamanti, and Universidade do Sagrado Coração.

\section{References}

Alijani, M., Kaleji, B. K., \& Rezaee, S. (2017). Improved visible light photocatalytic activity of $\mathrm{TiO}_{2}$ nano powders with metal ions doping for glazed ceramic tiles. Optical and Quantum Electronics, 49, 225-237. http://dx.doi.org/10.1007/s11082-017-1064-x

AQEG - Air Quality Expert Group. (2016). Paints and Surfaces for the Removal of Nitrogen Oxides. Retrieved from

https://uk-air.defra.gov.uk/assets/documents/reports/cat11/1604130958_PB14425_Paints_and_Surfaces_for the_Removal_of_Nitrogen_Oxides.pdf

ATSDR. (2007). Toxicological Profile for Benzene. Agency for Toxic Substances and Disease Registry (ATSDR), (August), 438.

Bianchi, C. L., Sacchi, B., Capelli, S., Pirola, C., Cerrato, G., Morandi, S., \& Capucci, V. (2017). Micro-sized $\mathrm{TiO}_{2}$ as photoactive catalyst coated on industrial porcelain grès tiles to photodegrade drugs in water. Environmental Science and Pollution Research, 30, 1-6. http://dx.doi.org/10.1007/s11356-017-9066-6

Bianchi, C. L., Colombo, E., Gatto, S., Stucchi, M., Cerrato, G., Morandi, S., \& Capucci, V. (2014). Photocatalytic degradation of dyes in water with micro-sized TiO 2 as powder or coated on porcelain-grès tiles. Journal of Photochemistry and Photobiology A: Chemistry, 280, 27-31. http://dx.doi.org/10.1016/j.jphotochem.2014.02.002

Bianchi, C. L., Gatto, S., Pirola, C., Scavini, M., Vitali, S., \& Capucci, V. (2013). Micro-TiO2 as a starting material for new photocatalytic tiles. Cement and Concrete Composites, 36(1), 116-120. http://dx.doi.org/10.1016/j.cemconcomp.2012.08.019

Bruno, P., Caselli, M., de Gennaro, G., Iacobellis, S., \& Tutino, M. (2008). Monitoring of volatile organic compounds in non-residential indoor environments. Indoor Air, 18(3), 250-256. http://dx.doi.org/10.1111/j.1600-0668.2008.00528.x

Chen, W., Zhang, J. S., \& Zhang, Z. (2005). Performance of air cleaners for removing multiple volatile organic compounds in indoor air. ASHRAE Transactions, 111(1), 1101-1114.

Cheng, L., Kang, Y., \& Li, G. (2012). Effect factors of benzene adsorption and degradation by nano-TiOimmobilized on diatomite. Journal of Nanomaterials, 2012. http://doi.org/10.1155/2012/593924

Czech, B., \& Buda, W. (2015). Photocatalytic treatment of pharmaceutical wastewater using new multiwall-carbon nanotubes/TiO2/SiO2 nanocomposites. Environmental Research, 137, 176-184. http://dx.doi.org/10.1016/j.envres.2014.12.006

Diamanti, M. V., Gadelrab, K. R., Pedeferri, M. P., Stefancich, M., Pehkonen, S. O., \& Chiesa, M. (2013). Nanoscale investigation of photoinduced hydrophilicity variations in anatase and rutile nanopowders. Langmuir, 29(47), 14512-14518. http://dx.doi.org/10.1021/la4034723

Diebold, U. (2003). The Surface Science of Titanium Dioxide. Applied Surface Science, 48(x), 53-229. http://dx.doi.org/10.1016/S0167-5729(02)00100-0

EPA. (2009). Residential Air Cleaners (Second Edition) A Summary of Available Information, EPA 402-F-09-002. Washington, DC.

Fujishima, A., \& Honda, K. (1972). Electrochemical Photolysis of Water at a Semiconductor Electrode. Nature, 238(5358), 37-38. http://dx.doi.org/10.1038/238037a0

Gallego, E., Roca, X., Perales, J. F., \& Guardino, X. (2009). Determining indoor air quality and identifying the origin of odour episodes in indoor environments. Journal of Environmental Sciences, 21(3), 333-339. http://dx.doi.org/10.1016/S1001-0742(08)62273-1

Graumann, T. (2013). Determination of the air purification performance of semiconducting photocayalytic materials by removing nitric oxide in accordance with ISO 22197-1. Retrieved from http://www.agrob-buchtal.de/ht/grafik/fraunhofer-braunschweig-schadstoffabbau-en.pdf

Guieysse, B., Hort, C., Platel, V., Munoz, R., Ondarts, M., \& Revah, S. (2008). Biological treatment of indoor air for VOC removal: Potential and challenges. Biotechnology Advances, 26(5), 398-410. 
http://dx.doi.org/10.1016/j.biotechadv.2008.03.005

Hadnadjev, M., Ranogajec, J., Petrovic, S., Markov, S., Ducman, V., \& Marinkovic-Neducin, R. (2010). Design of self-cleaning TiO 2 coating on clay roofing tiles. Philosophical Magazine, 90(22), 2989-3002. http://dx.doi.org/10.1080/14786431003767017

Hashimoto, K., Irie, H., \& Fujishima, A. (2005). $\mathrm{TiO}_{2}$ Photocatalysis: A Historical Overview and Future Prospects. Japanese Journal of Applied Physics, 44(12), 8269-8285. http://dx.doi.org/10.1143/JJAP.44.8269

Hasmaliza, M., Foo, H. S., \& Mohd, K. (2016). Anatase as Antibacterial Material in Ceramic Tiles. Procedia Chemistry, 19, 828-834. http://dx.doi.org/10.1016/j.proche.2016.03.109

Hodgson, A. T., Destaillats, H., Sullivan, D. P., \& Fisk, W. J. (2007). Performance of ultraviolet photocatalytic oxidation for indoor air cleaning applications. Indoor Air, 17(4), 305-316. http://dx.doi.org/10.1111/j.1600-0668.2007.00479.x

Hofer, M., \& Penner, D. (2011). Thermally stable and photocatalytically active titania for ceramic surfaces. Journal of the European Ceramic Society, 31(15), 2887-2896. http://dx.doi.org/10.1016/j.jeurceramsoc.2011.07.016

Huang, Y., Ho, S. S. H., Niu, R., Xu, L., Lu, Y., Cao, J., \& Lee, S. (2016). Removal of indoor volatile organic compounds via photocatalytic oxidation: A short review and prospect. Molecules, 21(1), 56-76. http://dx.doi.org/10.3390/molecules21010056

Huang, H., Liv, G., Zhan, Y., Xu, Y., Lu, H., \& Huang, H. (2016). Photocatalytic oxidation of gaseous benzene under VUV irradiation over $\mathrm{TiO}_{2}$ /zeolites catalysts. Catalysis Today, 281(3), 649-655. http://dx.doi.org/10.1016/j.cattod.2016.07.005

Kisch, H. (2011). Documentation of the photocatalytic reduction in acetaldehyde on tiles with HT coating. Retrieved from http://www.agrob-buchtal.de/ht/grafik/schadstoffabbau-prof-dr-kisch-en.pdf

Knook, E., \& Maanen, F. Van. (2013). Quantifying self-cleaning characteristics of surfaces, 31.

Lafuente, B., Downs, R. T., Yang, H., \& Stone, N. (2015). The power of databases: the RRUFF project. In Thomas Armbruster \& R. M. Danisi (Eds.), Highlights in Mineralogical Crystallography, 1-30.

Laufs, S., Burgeth, G., Duttlinger, W., Kurtenbach, R., Maban, M., Thomas, C., ... Kleffmann, J. (2010). Conversion of nitrogen oxides on commercial photocatalytic dispersion paints. Atmospheric Environment, 44(19), 2341-2349. http://doi.org/10.1016/j.atmosenv.2010.03.038

Mirzaei, A., Leonardi, S. G., \& Neri, G. (2016). Detection of hazardous volatile organic compounds (VOCs) by metal oxide nanostructures-based gas sensors: A review. Ceramics International, 42(14), 15119-15141. http://dx.doi.org/10.1016/j.ceramint.2016.06.145

Mohamed, A., El-Sayed, R., Osman, T. A., Toprak, M. S., Muhammed, M., \& Uheida, A. (2016). Composite nanofibers for highly efficient photocatalytic degradation of organic dyes from contaminated water. Environmental Research, 145, 18-25. http://dx.doi.org/10.1016/j.envres.2015.09.024

Neumann, F. (2013). Determination of the photocatalytic activity of tiles by the degradation of methylene blue based on ISO 10678:2010. from http://www.agrob-buchtal.de/ht/grafik/fraunhofer-reinigung-en.pdf

Petrick, K., Diedel, R., Peuker, M., Dieterle, M., Kuch, P., Kaden, R., ... Emmerich, K. (2011). Character and Amount of I-S Mixed-layer Minerals and Physicalchemical Parameters of Two Ceramic Clays from Westerwald, Germany: Implications for Processing Properties. Clays and Clay Minerals, 59(1), 58-74. http://dx.doi.org/10.1346/CCMN.2011.0590108

Sannino, D., Vaiano, V., Sarno, G., \& Ciambelli, P. (2013). Photocatalytic tiles for the preservation of indoor air quality. Chemical Engineering Transactions, 32, 9-10.

Schirmer, W. N., Pian, L. B., Szymanski, M. S. E., \& Gauer, M. A. (2011). Air pollution in internal environments and sick building syndrome. Ciência \& Saúde Coletiva, 16, 3583-3590. http://dx.doi.org/10.1590/S1413-81232011000900026

Solutions, C. (n.d.). HT tiles and grout: Hygienically clean and environmentally sustainable. Retrieved from http://www.ceramicsolutions.com.au/ht-tiles-grout-0

van der Zee, S. C., Fischer, P. H., \& Hoek, G. (2016). Air pollution in perspective: Health risks of air pollution 
expressed in equivalent numbers of passively smoked cigarettes. Environmental Research, 148, 475-483. http://dx.doi.org/10.1016/j.envres.2016.04.001

Vas, G., \& Vékey, K. (2004). Solid-phase microextraction: a powerful sample preparation tool prior to mass spectrometric analysis. Journal of Mass Spectrometry, 39(3), 233-254. http://dx.doi.org/10.1002/jms.606

Vulić, T. J., Rudić, O. L., \& Ranogajec, J. G. (2013). Characterization of photocatalytically active coatings based on $\mathrm{TiO}$ 2/Zn-Al layered double hydroxide on ceramic tiles. Acta Periodica Technologica, 44, 181-190. http://dx.doi.org/10.2298/APT1344181V

Yang, L., Wang, F., Shu, C., Liu, P., Zhang, W., \& Hu, S. (2017). $\mathrm{TiO}_{2} /$ porous cementitious composites: Influences of porosities and $\mathrm{TiO}_{2}$ loading levels on photocatalytic degradation of gaseous benzene. Construction and Building Materials, 150, 774-780. http://dx.doi.org/10.1016/j.conbuildmat.2017.06.004

Zhang, J. (Jensen) S., \& Wang, Z. (2010). Air Cleaning Technologies for Indoor Air Quality (ACT-IAQ): Growing Fresh and Clean Air. New York State energy research and development authority (NYSERDA).

\section{Copyrights}

Copyright for this article is retained by the author(s), with first publication rights granted to the journal.

This is an open-access article distributed under the terms and conditions of the Creative Commons Attribution license (http://creativecommons.org/licenses/by/4.0/). 